\title{
EDITORIAL NOTE ON WEIGHT-LENGTH RELATIONS OF FISHES
}

\author{
Rainer FROESE ${ }^{1 *}$, Athanassios C. TSIKLIRAS ${ }^{2,3}$, Konstantinos I. STERGIOU ${ }^{2}$ \\ ${ }^{1}$ Helmholtz Center of Ocean Research, GEOMAR, Kiel, Germany \\ ${ }^{2}$ Laboratory of Ichthyology, Department of Zoology, School of Biology, Aristotle University of Thessaloniki, \\ UP Box 134, 541 24, Thessaloniki, Greece \\ ${ }^{3}$ Department of Ichthyology and Aquatic Environment, University of Thessaly, 384 46, Volos, Greece
}

Froese R., Tsikliras A.C., Stergiou K.I. 2011. Editorial note on weight-length relations of fishes. Acta Ichthyol. Piscat. 41 (4): 261-263.

\begin{abstract}
Weight-length relations of fishes are useful for estimation of biomass from length observations, e.g., in fisheries or conservation research. Here we provide some guidance to authors of such papers, in order to facilitate the publication and review process.
\end{abstract}

The weight $(W)$ of fishes (and other organisms) is exponentially related to their length $(L)$ according to the equation $W=a L^{b}$, where $a$ is the intercept and $b$ is the slope of the log-transformed relation (Le Cren 1951, Froese 2006). Based on the slope $(b)$ of the relation between weight and length, one can check whether the growth of a fish species is isometric $(b=3$, all fish dimensions increase at the same rate), hypoallometric $(b<3$, a fish increases less in weight than predicted by its increase in length, i.e., it becomes more elongated as it grows; also termed negative allometric) or hyperallometric $(b>3$, a fish increases more in weight than predicted by its increase in length, i.e., it becomes less elongated or more roundish as it grows; also termed positive allometric). Weight-length relations (WLRs) can be used for converting lengths into biomass, determining fish condition, comparing fish growth among areas, and as a complement to species-specific reproduction and feeding studies (Petrakis and Stergiou 1995, Koutrakis and Tsikliras 2003, Froese 2006). Thus, they are an important component of fisheries biology and when properly calculated they can be very useful to fisheries management.

Over the last decade, the number of published articles dealing with WLRs of fishes is increasing in fast rate (Fig. 1). The majority of articles have been published in specialized fish journals, with 367 out of the 697 articles appearing in 16 journals (Journal of Applied Ichthyology: 124 articles, Fisheries Research: 40, Turkish Journal of Zoology: 30, Journal of Fish Biology: 24, Environmental Biology of Fishes: 16, Pakistan Journal of Zoology: 14, Cybium: 14, Hydrobiologia: 14, Acta Ichthyologica et Piscatoria: 13, Aquaculture: 13, Folia Zoologica: 12,
Turkish Journal of Veterinary and Animal Sciences: 12, North American Journal of Fisheries Management: 11, Acta Adriatica: 11, Journal of Fisheries and Aquatic Science: 10, Transactions of the American Fisheries Society: 10) and the remaining 330 articles in 144 journals. With respect to environment coverage, $51 \%$ of the articles refer to marine fish, $38 \%$ to freshwater fish and $11 \%$ to brackish/lagoon fish.

In this editorial note, we set some criteria and recommendations on important issues (i.e., number of species, sample size, length range and preservation, reporting and

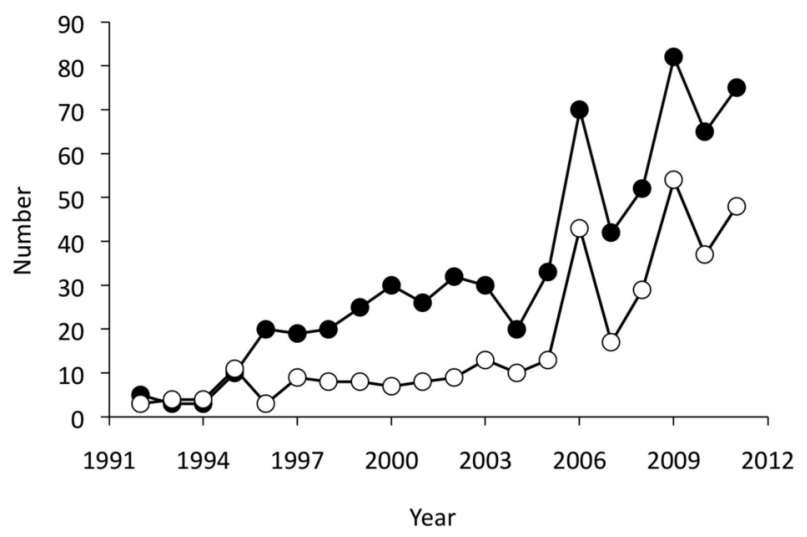

Fig. 1. The number of published articles on weight-length relations during 1992-2011 [based on data from Scopus (Anonymous 2011)]; The solid circles represent articles that included "length-weight relationships" in the title or abstract ( $n=662$ for 1992-2011 whereas 35 more articles have been published for the years before 1992), and the open circles those including "length-weight relationships" in their title only $(n=285)$

\footnotetext{
*Correspondence: Rainer Froese: rfroese@geomar.de; Athanassios C. Tsikliras: tsikliras@uth.gr; Konstantinos I. Stergiou: kstergio@bio.auth.gr.
} 
statistics) related to submitted manuscripts on WLR. These issues, which are based on and expanding those proposed by Froese (2006), are useful in order to improve the quality of related submissions, thus saving the time and effort of editors, reviewers and authors themselves.

Number of species, sample size, length range and preservation

1. At least 10 species should be included in a submission, including some for which no information on WLRs was previously available in FishBase (Froese and Pauly 2011); exceptions may apply when the work concerns very rare species or the biodiversity of a very restricted area, in which case less than 10 species could be included;

2. Adequate sample size of about 100 specimens, i.e., there is no need to kill thousands of specimens only for WLR estimates; for rare species fewer measurements are acceptable and sacrificed specimens should be deposited in a museum collection for further research; for endangered and protected species, nonlethal methods or specimens of opportunity (by-catch etc.) should be used;

3. Coverage of a the full size range (from juveniles to adults close to their asymptotic sizes), ideally with the number of specimens being equally distributed among size classes (e.g., 10 small, 10 medium-size, and 10 large specimens), in order to avoid over- or underestimation of $b$. Thus, samples taken with selective gear (e.g., a single mesh size of gillnets or a single hook size in longlines) are not generally appropriate because of the narrow length ranges sampled;

4. Ideally, the sampling period should extend over a full year cycle, but, in any case, all seasons should be covered;

5. The preservation technique should be clearly stated (and the duration the samples were preserved) and kept the same for all samples per species.

\section{Reporting and statistics}

1. The minimum and maximum length (preferably total length, in $\mathrm{cm}$ ) and weight (in $\mathrm{g}$ ) of the specimens per species should be available;

2. Before fitting a linear regression, the log-transformed data should be plotted and obvious outliers should be removed; the plots need not be included with the submission, but this procedure should be mentioned;

3 . From the linear regression of the log-transformed values, the slope $(b)$, the intercept $(a)$, their 95\% confidence limits, the coefficient of determination $\left(r^{2}\right)$, and the sample size $(n)$ of the WLRs, should be reported; note that $r^{2}<<0.95$ hints to remaining outliers: inclusion of extreme individuals such as early juveniles or aberrant adults, abrupt change of shape during development (stanzas), sex-differences, seasonal differences, etc., see Froese (2006) for details; These cases should be carefully re-examined;

4. When lists of species with WLRs are given, small deviations of $b$ from 3.0 can be ignored and need not be pointed out or discussed; large and consistent deviations, such as $b<2.6$ or $b>3.4$, should be re-evaluated (see Froese 2006 for possible causes) and if confirmed, discussed in an evolutionary context: how is fitness increased by the observed change in adult body shape?

5 . When a hypothesis on growth is tested, a statistical comparison for isometry $(b=3)$ can be done using available tests [see Pauly (1984) and Economou et al. (1991) for a special form of Student $t$-test] and should be reported together with the statistical level of significance;

6. When comparing two WLRs (e.g., for males and females of a species or between two areas), both the slopes and intercepts should be compared after the WLR has been logarithmically transformed (most statistical packages accommodate comparison of regression lines-see also Zar 1999). In case that WLRs do not differ between areas and sexes, data must be pooled (see also Froese 2006);

7. Comparisons of WLRs among sampling stations or with those in other areas are not necessary unless specific hypotheses are tested, in which case, all factors related to sampling (i.e., sample range, size range, type of length and weight, sex, preservation method, temporal resolution of sampling) should be kept equal;

8. The article of Le Cren (1951) is the pioneering work in WLRs and should be given full credit for leading the way;

9. A map of the study area is not necessary; coordinates of the sampling stations or of the broader area suffice;

10. WLRs could be made available to FishBase (Froese and Pauly 2011);

11. For other issues on WLRs related to condition factor, body form, within-species variation, the historical perspective, theoretical background and biological importance of WLRs, see Froese (2006).

\section{ACKNOWLEDGEMENTS}

The authors would like to thank the editor-in-chief Wojciech Piasecki and the editors and Board members of Acta Ichthyologica et Piscatoria: Peter Bartsch, Christian Capapé, Patrice Francour, Daniel Golani, Teresa Ostaszewska, Mirosław Przybylski, Harald Rosenthal, and Ekaterina D. Vasil'eva for their constructive comments that improved this editorial note.

\section{REFERENCES}

Anonymous 2011. Scopus. http://www.scopus.com [accessed on 25 November 2011].

Economou A.N., Daoulas Ch., Psarras T. 1991. Growth and morphological development of chub, Leuciscus cephalus (L.), during the first year of life. Journal of Fish Biology 39 (3): 393-408. DOI: $10.1111 / j .1095-8649.1991 . t b 04371 . x$

Froese R. 2006. Cube law, condition factor and weight-length relationships: history, meta-analysis and recommendations. Journal of Applied Ichthyology 22 (4): 241-253. DOI: 10.1111/j.1439-0426.2006.00805.x

Froese R., Pauly D. (eds.) 2011. FishBase. [version 10/2011] http://www.fishbase.org. 
Koutrakis E.T., Tsikliras A.C. 2003. Length-weight relationships of fishes from three northern Aegean estuarine systems (Greece). Journal of Applied Ichthyology 19 (4): 258-260. DOI: 10.1046/j.1439-0426.2003.00456.x

Le Cren E.D. 1951. The length-weight relationship and seasonal cycle in gonad weight and condition in the perch (Perca fluviatilis). Journal of Animal Ecology 20 (2): 201-219.

Pauly D. 1984. Fish population dynamics in tropical waters: a manual for use with programmable calculators. International Center for Living Aquatic Resources Management, Studies and Reviews No. 8.
Petrakis G., Stergiou K.I. 1995. Weight-length relationships for 33 fish species in Greek waters. Fisheries Research 21 (3-4): 465-469. DOI: 10.1016/0165-7836(94)00294-7

Zar J.H. 1999. Biostatistical Analysis. Prentice-Hall, Upper Saddle River, NJ, USA.

Received: 27 October 2011 Accepted: 19 December 2011 Published electronically: 31 December 2011 